\title{
Thermal evolution of structure and photocatalytic activity in polymer microsphere templated $\mathrm{TiO}_{2}$ microbowls ${ }^{\text {th }}$
}

\author{
Deniz Altunoz Erdogan ${ }^{\mathrm{a}}$, Meryem Polat ${ }^{\mathrm{a}}$, Ruslan Garifullin ${ }^{\mathrm{b}}$, \\ Mustafa O. Guler ${ }^{\mathrm{b}}$, Emrah Ozensoy ${ }^{\mathrm{a}, *, 1}$ \\ a Department of Chemistry, Bilkent University, 06800 Ankara, Turkey \\ ${ }^{\mathrm{b}}$ Institute of Materials Science and Nanotechnology, National Nanotechnology Research Center (UNAM), Bilkent University, 06800 Ankara, Turkey
}

\section{A R T I C L E I N F O}

\section{Article history:}

Received 22 January 2014

Received in revised form 4 April 2014

Accepted 12 April 2014

Available online 21 April 2014

\section{Keywords:}

$\mathrm{TiO}_{2}$

Photocatalyst

Cross-linked divinyl benzene

$\mathrm{NO}(\mathrm{g})$ oxidation

Rhodamine B

\begin{abstract}
A B S T R A C T
Polystyrene cross-linked divinyl benzene (PS-Co-DVB) microspheres were used as an organic template in order to synthesize photocatalytic $\mathrm{TiO}_{2}$ microspheres and microbowls. Photocatalytic activity of the microbowl surfaces were demonstrated both in the gas phase via photocatalytic $\mathrm{NO}(\mathrm{g})$ oxidation by $\mathrm{O}_{2}(\mathrm{~g})$ as well as in the liquid phase via Rhodamine B degradation. Thermal degradation mechanism of the polymer template and its direct influence on the $\mathrm{TiO}_{2}$ crystal structure, surface morphology, composition, specific surface area and the gas/liquid phase photocatalytic activity data were discussed in detail. With increasing calcination temperatures, spherical polymer template first undergoes a glass transition, covering the $\mathrm{TiO}_{2}$ film, followed by the complete decomposition of the organic template to yield $\mathrm{TiO}_{2}$ exposed microbowl structures. $\mathrm{TiO}_{2}$ microbowl systems calcined at $600^{\circ} \mathrm{C}$ yielded the highest per-site basis photocatalytic activity. Crystallographic and electronic properties of the $\mathrm{TiO}_{2}$ microsphere surfaces as well as their surface area play a crucial role in their ultimate photocatalytic activity. It was demonstrated that the polymer microsphere templated $\mathrm{TiO}_{2}$ photocatalysts presented in the current work offer a promising and a versatile synthetic platform for photocatalytic DeNO ${ }_{x}$ applications for air purification technologies.
\end{abstract}

(C) 2014 Elsevier B.V. All rights reserved.

\section{Introduction}

Shape-defined nano and micro scale titanium dioxide $\left(\mathrm{TiO}_{2}\right)$ structures are widely utilized as photocatalytic systems; where they have attracted a particular interest in environmental applications. It has been reported that controlling particle shape, geometry, size, surface morphology, electronic structure, relative abundance of anatase/rutile surface domains and the nature of the surface functional groups (such as $-\mathrm{OH}$ ) are some of the key factors for designing efficient $\mathrm{TiO}_{2}$ photocatalytic architectures [1-5].

$\mathrm{TiO}_{2}$ materials can be produced with unique morphologies, shapes and structures at the micro/nanoscale revealing extraordinary physical, chemical, electronic and optical properties, rendering these systems very versatile photocatalysts [3]. Template directed synthesis is one of the approaches for fine-tuning size,

\footnotetext{
is Electronic Supplementary Information (ESI) available: Gas-phase and solutionphase photocatalytic performence of P25.

* Corresponding author. Tel.: +90 312290 2121; fax: +90 3122664068 .

E-mail address: ozensoy@fen.bilkent.edu.tr (E. Ozensoy).

1 Web: http://www.fen.bilkent.edu.tr/ ozensoy.
}

shape and porosity of $\mathrm{TiO}_{2}$ particles [6-8]. In particular, utilization of organic templates such as polymers offers vast opportunities for controlling the shapes of inorganic materials at the micrometer/nanometer scale. Such strategies can be exploited to synthesize shape-defined $\mathrm{TiO}_{2}$ materials exhibiting nano/micro spheres [9], hollow structures [10], tubes [11], wires [3], core-shell structures [3], and egg-yolk structures [12].

In the current report, $\mathrm{TiO}_{2}$ microbowls were synthesized by using polystyrene crosslinked divinyl benzene (PS-co-DVB) microspheres. The polymer template was removed by calcination and $\mathrm{TiO}_{2}$ microbowls were produced. The effect of the calcination temperature on the structural properties and activity of the photocatalysts were studied in the gas phase as well as in the solution phase oxidation reactions.

\section{Experimental}

\subsection{Sample preparation}

A custom sol-gel method combined with a polymer templating technique was used for the synthesis of $\mathrm{TiO}_{2}$ microbowl structures 


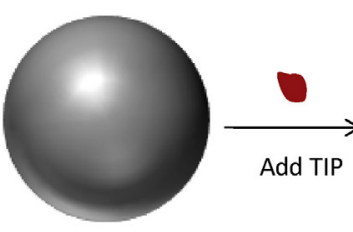

Ps-co-DVB micro-sphere

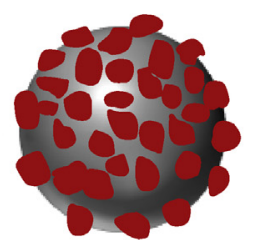

Ps-co-DVB soaked with TIP

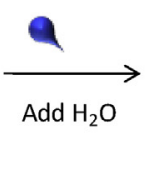

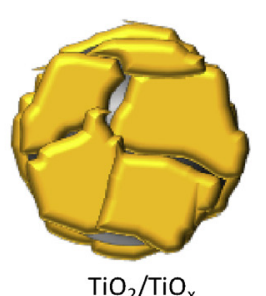

coated microsphare

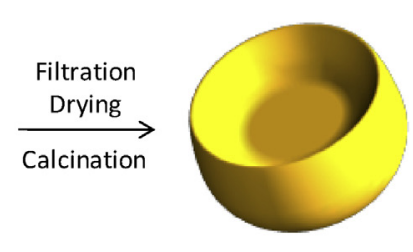

$\mathrm{TiO}_{2}$ micro-bowls

Scheme 1. Synthetic protocol for PS-co-DVB-templated $\mathrm{TiO}_{2}$ microspheres and microbowls.

[13-15]. Commercially available polystyrene cross-linked divinyl benzene (PS-co-DVB) microspheres (Aldrich) with an average particle size of ca. $8 \mu \mathrm{m}$ were used as the template material. Preparation of $\mathrm{TiO}_{2}$ microspheres and microbowls is shown in Scheme 1. First, equal masses (i.e. $1.0 \mathrm{~g}$ ) of polymer microspheres and titanium(IV) isopropoxide (TIP, 97\%, Aldrich) were mixed and stirred for $24 \mathrm{~h}$ under ambient conditions. Then, $100 \mathrm{~mL}$ of deionized water (Milli$Q, 18.2 \mathrm{M} \Omega \mathrm{cm}$ ) was added to the mixture under continuous stirring ( $24 \mathrm{~h})$, where hydrolysis and condensation reactions were carried out. Then, microspheres were vacuum-filtered, washed with deionized water and dried for $24 \mathrm{~h}$ at $60^{\circ} \mathrm{C}$ in air. Later, the sample was calcined in air in order to remove the polymer template as well as to crystallize the inorganic component (i.e. $\mathrm{TiO}_{2}$ ). Samples were calcined at various temperatures $(200,300,400,500,600$, $700^{\circ} \mathrm{C}$ ) in air for $2 \mathrm{~h}$ (using a heating rate of $8^{\circ} \mathrm{C} / \mathrm{min}$ ) to control crystallinity and surface morphology of $\mathrm{TiO}_{2}$ microspheres. Synthesized samples were named as PsTi-200, PsTi-300, PsTi-400, PsTi-500, PsTi-600, and PsTi-700 depending on the calcination temperature.

\subsection{Structural characterization}

The morphology and the particle size of the polymer templated $\mathrm{TiO}_{2}$ microspheres and microbowls were investigated by using a Carl-Zeiss Evo40 environmental scanning electron microscope (SEM) equipped with a Bruker energy dispersive X-Ray (EDX) detector. Determination of the crystal structure of the synthesized materials were carried out with a Rigaku Miniflex X-ray diffractometer (XRD) equipped with $\mathrm{Cu} K \alpha$ radiation operated at $30 \mathrm{kV}$, $1.54 \AA$ and $15 \mathrm{~mA}$. The XRD patterns were recorded in the $2 \theta$ range of $10-60^{\circ}$ with a step width of $0.02 \mathrm{~s}^{-1}$. Raman spectra of the samples were collected in the range of $200-1500 \mathrm{~cm}^{-1}$ with a resolution of $4 \mathrm{~cm}^{-1}$ using a Horiba Jobin Yvon LabRAM HR800 spectrometer equipped with a confocal Raman BX41 microscope. The Raman spectrometer was equipped with a Nd:YAG laser $(\lambda=532.1 \mathrm{~nm})$ where the laser power was $20 \mathrm{~mW}$. The thermal properties of the $\mathrm{TiO}_{2}$ systems were also investigated by using thermo gravimetric analysis (TGA). TGA measurements were carried out between 30 and $800^{\circ} \mathrm{C}$ (at a heating rate of $10^{\circ} \mathrm{C} / \mathrm{min}$ and under nitrogen flow) by using a TA Instruments TGA-Q500 setup. The specific surface area (SSA) of the $\mathrm{TiO}_{2}$ samples was determined by conventional Brunauer-Emmett-Teller (BET) $\mathrm{N}_{2}$ adsorption method with a Micromeritics Tristar 3000 surface area and pore size analyzer. Prior to the BET measurements, all of the samples were out gassed in vacuum for $2 \mathrm{~h}$ at $150^{\circ} \mathrm{C}$.

\subsection{Photocatalytic performance analysis measurements}

\subsubsection{Gas-phase photocatalytic oxidation performance measurements}

Reactivity of the $\mathrm{TiO}_{2}$ microstructures was studied via photocatalytic $\mathrm{NO}$ oxidation $\left(\mathrm{NO}(\mathrm{g})+1 / 2 \mathrm{O}_{2}(\mathrm{~g}) \rightarrow \mathrm{NO}_{2}(\mathrm{~g})\right)$. The gas phase photocatalytic activity of the $\mathrm{TiO}_{2}$ microstructures was analyzed in a custom-made continuous flow reaction system, which is shown in Scheme 2. The experimental setup was comprised of a highpurity gas mixture containing $\mathrm{NO}(\mathrm{g})$ ( $100 \mathrm{ppm} \mathrm{NO}(\mathrm{g})$ in $\mathrm{N}_{2}$ (g), Linde $\mathrm{GmbH}), \mathrm{O}_{2}(\mathrm{~g})(99.998 \%$, Linde $\mathrm{GmbH})$ and $\mathrm{N}_{2}(\mathrm{~g})(99.998 \%$, Linde $\mathrm{GmbH}$ ) which was humidified with $70 \% \mathrm{RH}$ (relative humidity, measured via a Hanna HI 9565 humidity analyzer at the sample position in the photocatalytic reactor). In a typical gas phase photocatalytic performance analysis test, a total gas flow rate of 1 SLM (SLM, standard liters per minute) was used, where the volumetric flow rates of $\mathrm{N}_{2}(\mathrm{~g}), \mathrm{O}_{2}(\mathrm{~g})$ and $\mathrm{NO}(\mathrm{g})$ were set to be 0.750 SLM, 0.250 SLM and 0.010 SLM via mass flow controllers (MFCs, MKS, 1479A), respectively. Before the performance tests, synthesized $\mathrm{TiO}_{2}$ microsphere/microbowl powder samples were dispersed on a poly-methyl methacrylate (PMMA) sample holder $\left(2 \times 40 \times 40 \mathrm{~mm}^{3}\right)$ and irradiated with UVA illumination (Sylvania UV-lamp, black-light, F8W, T5, $368 \mathrm{~nm}$ ) under ambient conditions for $18 \mathrm{~h}$ in order to remove the surface contaminations and to activate the photocatalysts. After this activation and decontamination procedure, samples were inserted into the photocatalytic flow reactor for performance analysis. UVA illumination source used in the performance analysis tests (Sylvania UV-lamp, black-light, F8W, T5, $368 \mathrm{~nm}$ ) generated a UVA photon flux of $7.5 \mathrm{~W} / \mathrm{m}^{2}$ at the sample position under typical reaction conditions. During the performance tests, reaction gases were swept over a $950 \mathrm{mg}$ photocatalyst sample and the concentration of $\mathrm{NO}(\mathrm{g}), \mathrm{NO}_{2}(\mathrm{~g})$ and total $\mathrm{NO}_{x}$ (g) species in the photocatalytic reactor were quantitatively measured online with a Horiba APNA-370 chemiluminiscence $\mathrm{NO}_{x}$ analyzer.

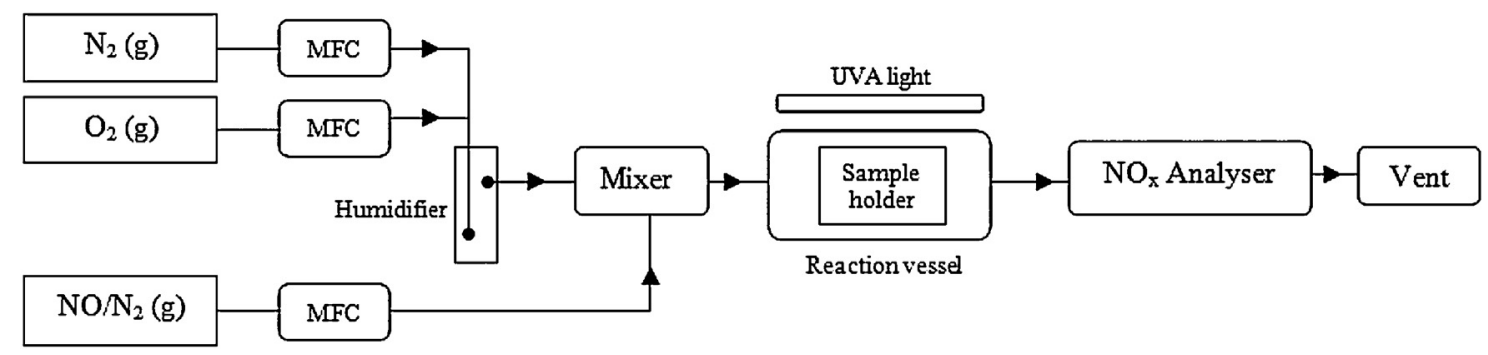

Scheme 2. Gas-phase photocatalytic performance analysis setup. 
Gas phase photocatalytic activity measurements are reported in terms of percent photonic efficiencies $(\zeta \%)$ as described in Eqs. (1) and (2).

$\zeta \%=\frac{n_{\mathrm{NO}_{x}}}{n_{\text {photon }}} \times 100$

where $n_{\mathrm{NO}_{x}}$ corresponds to either the decrease in the total number of moles of all gaseous $\mathrm{NO}_{x}$ species or the number of moles of $\mathrm{NO}_{2}(\mathrm{~g})$ generated in a $60 \mathrm{~min}$ (i.e. $3600 \mathrm{~s}$ ) photocatalytic performance test. On the other hand, $n_{\text {photon }}$ corresponds to the total number of moles of incident UVA photons impinging on the catalyst surface in $3600 \mathrm{~s}$, which can be calculated through Eq (2) as:

$n_{\text {photon }}=\frac{(I \lambda S t)}{(N h c)}$

where I represents the photon power density of the UVA lamp, experimentally measured at the sample position in the photocatalytic reactor (typically, $7.5 \mathrm{~W} / \mathrm{m}^{2}$ ), $\lambda$ is the representative emission wavelength of the UVA lamp (i.e. $368 \mathrm{~nm}$ ), $S$ is the surface area of the photocatalyst sample holder in the reactor that is exposed to the UVA irradiation (i.e. $4 \mathrm{~cm} \times 4 \mathrm{~cm}=16 \mathrm{~cm}^{2}$ ); $t$ is the duration of the performance test (i.e. $3600 \mathrm{~s}$ ), $N$ is the Avogadro's number, $h$ is Planck's constant and $c$ is the speed of light.

\subsubsection{Liquid-phase photocatalytic oxidation performance measurements}

Liquid-phase photocatalytic oxidation activity of the $\mathrm{TiO}_{2}$ microstructures was demonstrated by photodegradation [16-18]. Oxidative degradation of Sulforhodamine B (RhB, 95\%, Sigma) under UVA irradiation (Sylvania UV-lamp, F8W, T5, Black-light, $8 \mathrm{~W}, 368 \mathrm{~nm}$ ) was conducted in a batch-mode photocatalytic reactor of dimensions $45 \times 23 \times 28 \mathrm{~cm}^{3}$. An aqueous $\mathrm{RhB}$ solution at concentration of $1 \mathrm{mg} / \mathrm{L}$ and $30 \mathrm{mg}$ of $\mathrm{TiO}_{2}$ microstructures was added into the reactor and stirred continuously at a stirring rate of $100 \mathrm{rpm}$. Then, the photocatalytic degradation process was studied by measuring the change in the dye concentration with an UV-vis spectrophotometer (Carry 300, Agilent). Attenuation of the major absorption band of RhB $(564 \mathrm{~nm})$ associated with the $S_{0} \rightarrow S_{1}$ absorption [19] was recorded every 30 min until the test solution became visually transparent. Before the UV-vis absorption measurements, test solutions were centrifuged and the absorbance of the filtrate was recorded. By using a calibration curve $\left(R^{2}=9994\right)$ of the dye solution, the percent decolorization efficiency $\left(D_{\mathrm{ef}}\right)$ of the system at an irradiation time $t(\mathrm{~min})$ was calculated as described in Eq. (3) [20].

$D_{e f}(\%)=\frac{\left(C_{0}-C_{t}\right)}{C_{0}} \times 100$

In Eq. (3), $C_{0}$ and $C_{t}$ represent the concentration of the test solution before and after irradiation at time $t$, respectively. A plot of $C_{0} / C$ versus irradiation time $(t)$ determines the decolorization degree of the test solution.

\section{Results and discussion}

\subsection{Structural characterization of polymer-templated $\mathrm{TiO}_{2}$ microstructures}

The SEM images in Fig. 1a-d illustrate the morphology and the particle size of the $\mathrm{TiO}_{2}$ coated PS-Co-DVB microspheres. The particle size variation in the microstructures stems from the corresponding size distribution in the nascent commercial PS-Co-DVB material. SEM images in Fig. 1a-d and the corresponding EDX measurements (Fig. 1e) of the $\mathrm{TiO}_{2}$-coated microspheres revealed that the surface of the polymer microspheres was coated with a thin layer of $\mathrm{TiO}_{2}$ and additional $\mathrm{TiO}_{2}$ was also further deposited.
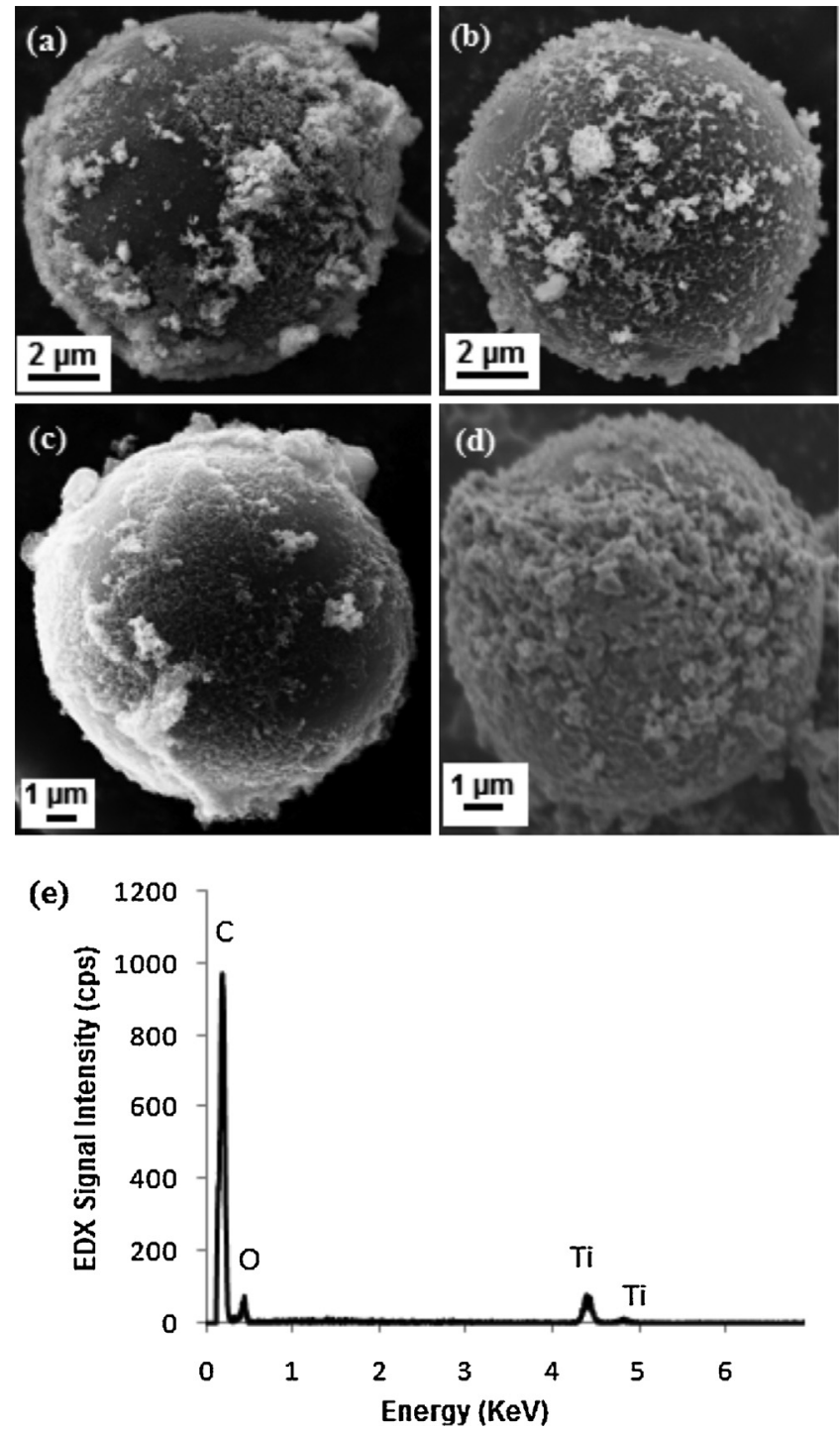

Fig. 1. (a-d) SEM images and (e) a representative EDX spectrum of $\mathrm{TiO}_{2}$-coated PS-co-DVB microspheres before calcination.

Upon calcination of the $\mathrm{TiO}_{2}$ coated PS-co-DVB microspheres between 200 and $700^{\circ} \mathrm{C}$, significant morphological changes were observed. The microspheres were converted into microbowls (Fig. 2). This observation was also accompanied by a considerable weight loss, which will be discussed further in the text (Fig. 3). Fig. 2 shows the SEM images and the corresponding EDX spectrum of the polymer-templated $\mathrm{TiO}_{2}$ microbowls, which were calcined at $600^{\circ} \mathrm{C}$ at ambient conditions for $2 \mathrm{~h}$. Due to decomposition of the polymer template and the associated formation of $\mathrm{H}_{x} \mathrm{C}_{y}(\mathrm{~g})$ and $\mathrm{H}_{x} \mathrm{C}_{y} \mathrm{O}_{z}(\mathrm{~g})$, pressure accumulation inside the microsphere leads to the rupture of the spherical morphology during the evolution of the entrapped gas. The resulting open microbowl structures are shown in the inset of Fig. 2b. The interior cavities of the microbowls have an average diameter of $8 \mu \mathrm{m}$ with an average wall thickness of $600 \mathrm{~nm}$. The EDX spectrum of the microbowls (Fig. 2b) indicates $\mathrm{TiO}_{2} / \mathrm{TiO}_{x}$ content with a relatively minor contribution of carbon-based species. On the other hand, EDX spectrum of the same samples before the calcination revealed excessive $C$ signal (Fig. 1e).

Evolution of $\mathrm{H}_{x} \mathrm{C}_{y}(\mathrm{~g})$ and $\mathrm{H}_{x} \mathrm{C}_{y} \mathrm{O}_{z}(\mathrm{~g})$ and the anticipated weight loss of the sample upon the decomposition/degradation of the polymer template below $600^{\circ} \mathrm{C}$ is in perfect agreement with the TGA results shown in Fig. 3, which show a sharp gravimetric loss 

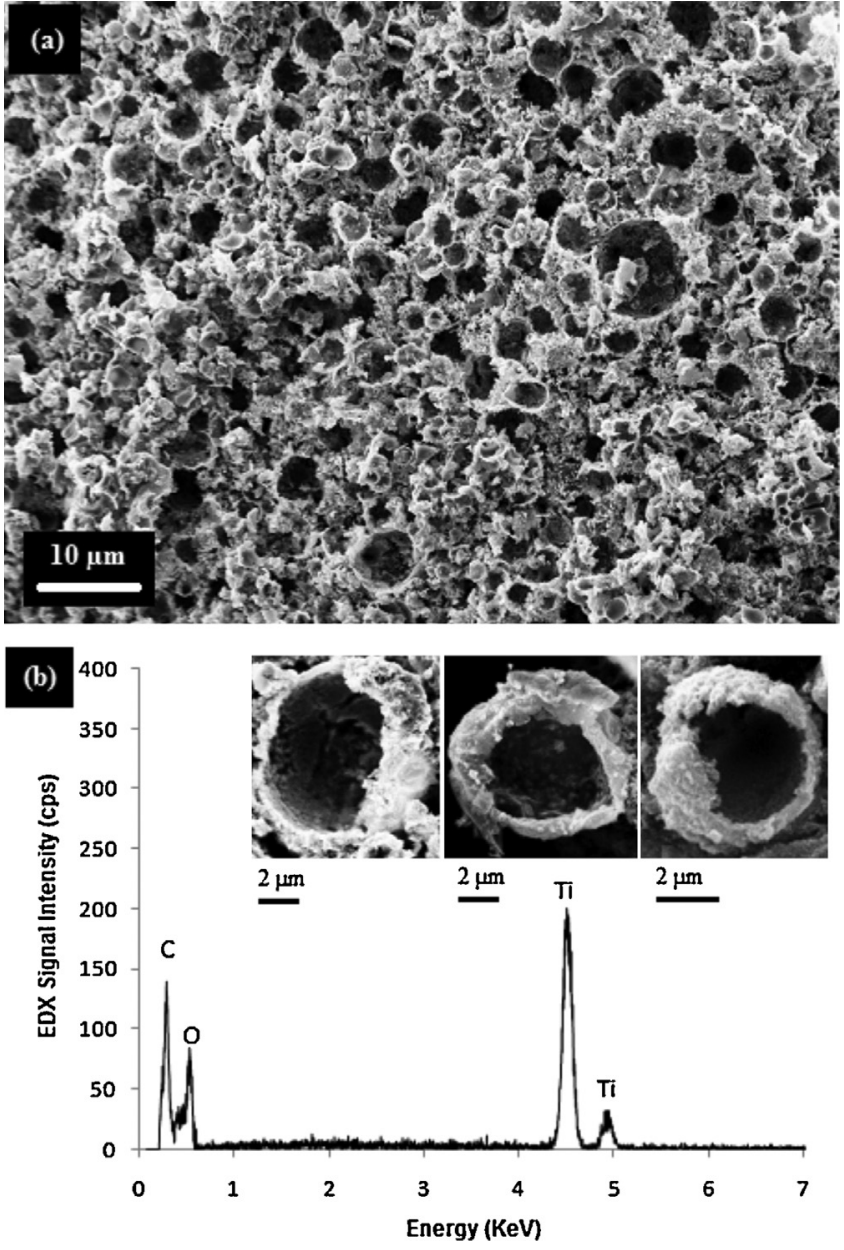

Fig. 2. (a) SEM image, (b) EDX spectrum of PS-Co-DVB templated $\mathrm{TiO}_{2}$ microbowls after calcination at $600{ }^{\circ} \mathrm{C}$ for $2 \mathrm{~h}$ (inset shows the detailed morphology of the microbowls in SEM).

within $400-500^{\circ} \mathrm{C}$. The TGA curve of $\mathrm{TiO}_{2}$-coated PS-co-DVB microspheres (Fig. 3) exhibits a $2.7 \mathrm{wt} \%$ loss in the temperature range of $30-250{ }^{\circ} \mathrm{C}$ due to the evaporation of water and other volatile organics. $\mathrm{TiO}_{2}$ reveals a negligible gravimetric loss within $30-800^{\circ} \mathrm{C}$, while pure/uncoated polystyrene undergoes almost $100 \mathrm{wt} \%$ loss within $300-500{ }^{\circ} \mathrm{C}$ due to decomposition/degradation [21-23].

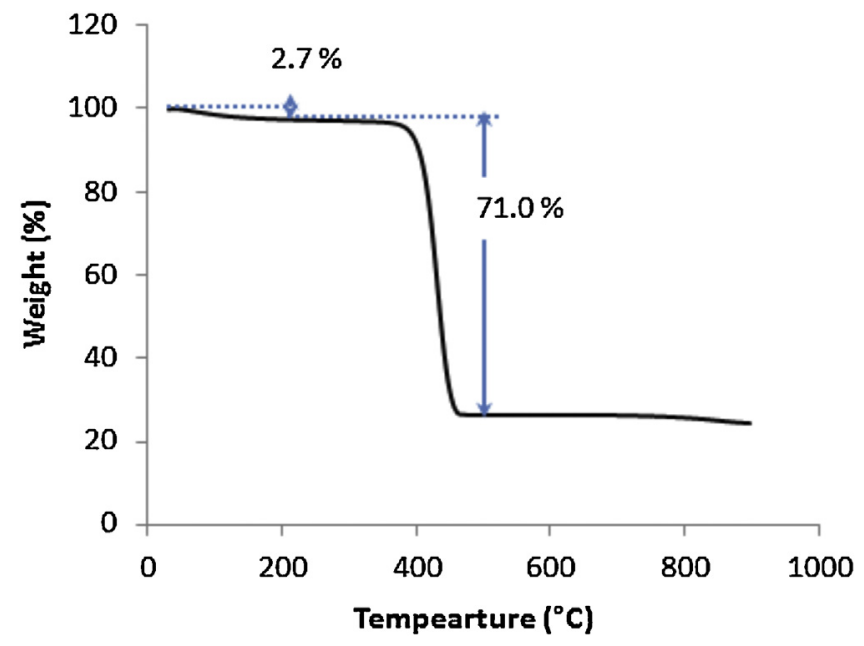

Fig. 3. TGA measurement for PS-co-DVB templated $\mathrm{TiO}_{2}$ microspheres.
Thus, TGA data in Fig. 3, suggest that after the $71 \mathrm{wt} \%$ loss at $T>400^{\circ} \mathrm{C}$, a large portion of the remaining sample, which corresponds to $29 \%$ of the original sample weight, is due to the inorganic content (i.e. $\mathrm{TiO}_{2}$ ).

In order to investigate the influence of the calcination temperature on the photocatalyst structure and the photocatalytic activity, samples were calcined at different temperatures within $200-700^{\circ} \mathrm{C}$. Corresponding XRD patterns and Raman spectra of these samples are presented in Fig. 4. Calcination at 200 and $300{ }^{\circ} \mathrm{C}$ leads to the formation of an amorphous $\mathrm{TiO}_{2} / \mathrm{TiO}_{x}$ structure, which starts to crystallize into a rather disordered anatase phase at $400^{\circ} \mathrm{C}$ with a small average particle size, evident from the corresponding broad anatase XRD diffraction signals (ICDD Card No: 21-1272) in Fig. 4a and the characteristically intense anatase Raman scattering observed at $144 \mathrm{~cm}^{-1}$ [24-26]. At $500^{\circ} \mathrm{C}$, a well-ordered anatase phase with a larger average particle size is formed as can be seen from the sharp and intense anatase signals in both XRD (Fig. 4a) and Raman (Fig. 4b) results. At this temperature, rutile phase also appears as a secondary phase in both XRD results shown in Fig. 4a (ICDD card no: 04-0551) as well as in the Raman data in Fig. 4b. Formation of the rutile phase leads to the evolution of typical Raman scattering features at $236,447,612,826 \mathrm{~cm}^{-1}$ [24-26]. Rutile phase becomes more crystalline and abundant at higher calcination temperatures. Upon calcination at $700{ }^{\circ} \mathrm{C}$, rutile becomes the dominant phase, although anatase phase can still be detected as a secondary phase (Fig. 4a and b).

\subsection{Photocatalytic activity of the polymer-templated $\mathrm{TiO}_{2}$ microspheres and microbowls}

\subsubsection{Gas-phase photocatalytic oxidation performance}

The photocatalytic $\mathrm{NO}(\mathrm{g})$ oxidation with $\mathrm{O}_{2}(\mathrm{~g})$ was used as a model reaction [27-32]. Fig. 5 illustrates a typical gas phase photocatalytic performance analysis test in which the photocatalyst sample is exposed to a feed gas mixture containing $1 \mathrm{ppm} \mathrm{NO}(\mathrm{g})$ as well as a certain composition of $\mathrm{N}_{2}(\mathrm{~g})$ and $\mathrm{O}_{2}(\mathrm{~g})$ with a $70 \% \mathrm{RH}$ (see Section 2 for details). Fig. 5 shows the time-dependent profiles for the total $\mathrm{NO}_{x}$ concentration (i.e. sum of the concentrations of all of the $\mathrm{NO}_{x}$ species existing in the reactor, i.e. blue curve in Fig. 5) as well as separate $\mathrm{NO}(\mathrm{g})$ (black curve) and $\mathrm{NO}_{2}(\mathrm{~g})$ (red curve) concentrations in the photocatalytic reactor measured by the chemiluminiscence $\mathrm{NO}_{x}$ analyzer. As shown in Fig. 5, during the initial $15 \mathrm{~min}$ of the performance test, gas mixture containing $1 \mathrm{ppm} \mathrm{NO}(\mathrm{g})$ is fed to the photocatalyst while UVA lamp is in off position and the reactor is kept in dark in order to prevent any exposure to sunlight. This leads to a minor transient fall in the total $\mathrm{NO}_{x}(\mathrm{~g})$ and $\mathrm{NO}(\mathrm{g})$ concentrations, which is associated with the dilution of the gas in the reactor pipeline and the thermal adsorption of $\mathrm{NO}_{x}$ species on the gas lines, reactor walls as well as on the photocatalyst surface. As the system is kept in dark under these conditions, no photocatalytic activity is observed during this initial stage, which is evident by the lack of any $\mathrm{NO}_{2}(\mathrm{~g})$ production. After the initial transient period, reactor walls and the photocatalyst surface are saturated with $\mathrm{NO}_{x}$, after which $\mathrm{NO}_{x}(\mathrm{~g})$ and $\mathrm{NO}(\mathrm{g})$ traces quickly return to the original inlet concentration value of $1 \mathrm{ppm}$.

Next, UVA lamp is turned on and the photocatalytic reaction is started. Upon UVA radiation, a sharp and a permanent fall in the $\mathrm{NO}(\mathrm{g})$ and total $\mathrm{NO}_{x}(\mathrm{~g})$ concentrations along with a quick rise in $\mathrm{NO}_{2}(\mathrm{~g})$ signal, were observed. This is caused by conversion of $\mathrm{NO}(\mathrm{g})$ into $\mathrm{NO}_{2}(\mathrm{~g})$ via photocatalytic oxidation. In addition, generated $\mathrm{NO}_{2}(\mathrm{~g})$ can also adsorb on the photocatalyst surface in the form of chemisorbed $\mathrm{NO}_{2}$, nitric/nitrous acid, nitrites and nitrates [24-26,33] and stored in the solid state, leading to a further decrease in the $\mathrm{NO}(\mathrm{g})$ signal. Furthermore, direct photocatalytic decomposition and photo-reduction of $\mathrm{NO}(\mathrm{g})$ forming $\mathrm{N}_{2}(\mathrm{~g})$ 

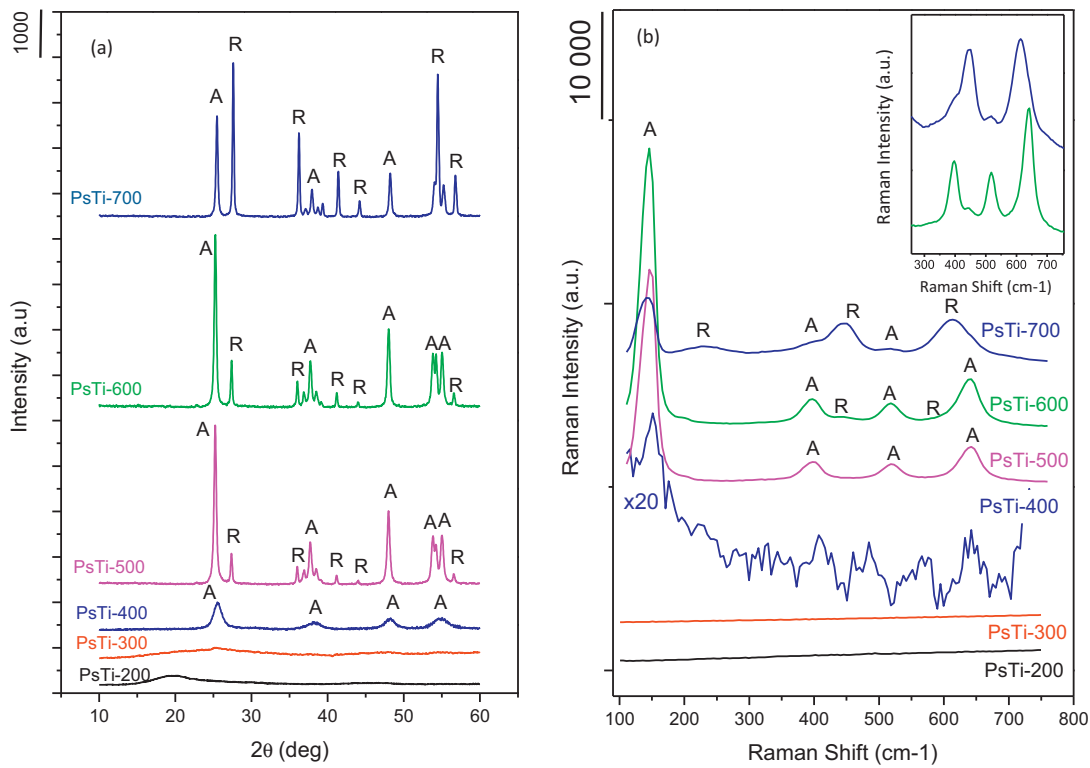

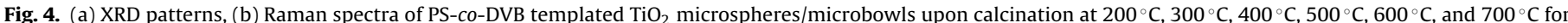
$2 \mathrm{~h}$ under ambient conditions (inset highlights the detailed Raman features of PsTi-600 and PsTi-700 samples). A: anatase, R: rutile.

and/or $\mathrm{N}_{2} \mathrm{O}(\mathrm{g})$ cannot be ruled out [34]. The total $\mathrm{NO}_{x}$ concentration (blue) curve (which is mostly comprised of the sum of $\mathrm{NO}(\mathrm{g})$ and $\mathrm{NO}_{2}(\mathrm{~g})$ signals) in Fig. 5 stays always below 1 ppm during the UVA-activated regime, illustrating the continuous photocatalytic activity.

Gas-phase photocatalytic performance tests similar to the one given in Fig. 5 were also performed on other PS-co-DVB templated $\mathrm{TiO}_{2}$ microsphere/microbowl photocatalysts, which were calcined at various temperatures between 200 and $700{ }^{\circ} \mathrm{C}$. Percent photonic efficiency values derived from such experiments are shown in Fig. 6, where blue bars represent the \% photonic efficiency of total $\mathrm{NO}_{x}(\mathrm{~g})$ decrease, while red bars correspond to the \% photonic efficiency of $\mathrm{NO}_{2}(\mathrm{~g})$ production.

Fig. 6 shows that PsTi-200 sample reveals both considerable $\mathrm{NO}_{x}$ storage (blue bar) and $\mathrm{NO}_{2}(\mathrm{~g})$ production (red bar) capabilities.

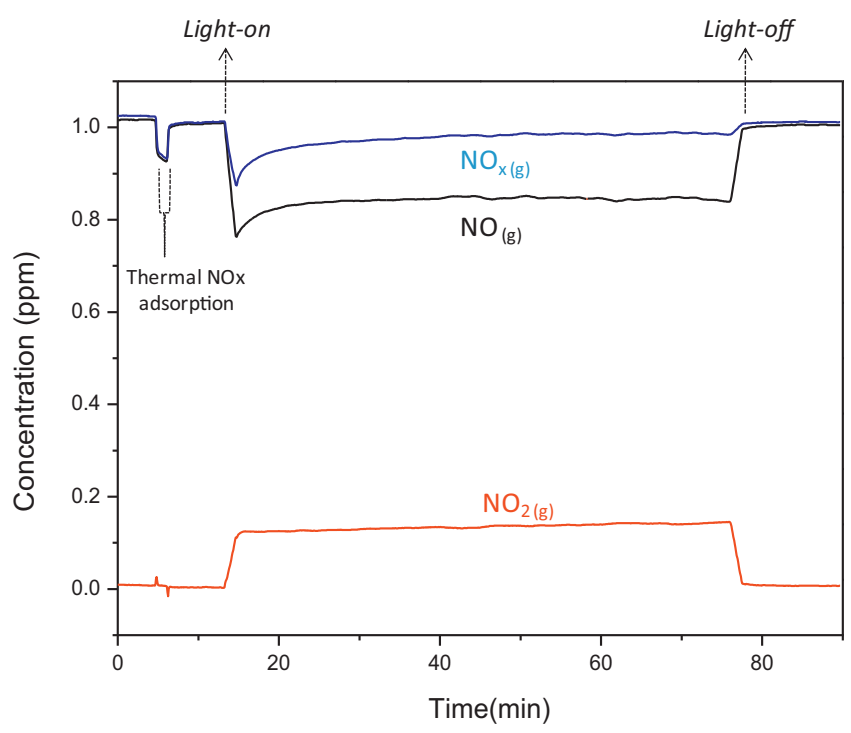

Fig. 5. Typical time-dependent concentration profiles for total $\mathrm{NO}_{x}(\mathrm{~g}), \mathrm{NO}(\mathrm{g})$ and $\mathrm{NO}_{2}(\mathrm{~g})$ over PS-co-DVB templated $\mathrm{TiO}_{2}$ microbowl photocatalyst (PsTi-600) during gas-phase photocatalytic NO oxidation activity tests. (For interpretation of the references to color in this figure legend, the reader is referred to the web version of this article.)
On the other hand, upon increasing the calcination temperature to $300^{\circ} \mathrm{C}$, both $\mathrm{NO}_{x}$ storage and $\mathrm{NO}_{2}(\mathrm{~g})$ production performances were observed to decline drastically. On the other hand, after calcination at $400^{\circ} \mathrm{C}, \mathrm{NO}_{x}$ storage capability is recovered while $\mathrm{NO}_{2}(\mathrm{~g})$ production is still noticeably suppressed. Above $500^{\circ} \mathrm{C}$, although $\mathrm{NO}_{x}$ storage capacity decreases to a certain extent, $\mathrm{NO}_{2}(\mathrm{~g})$ production capability is fully regained, reaching its highest value at $600^{\circ} \mathrm{C}$. Increasing the calcination temperature to $700^{\circ} \mathrm{C}$ leads to a decrease in the $\mathrm{NO}_{x}$ storage and $\mathrm{NO}_{2}(\mathrm{~g})$ production performances simultaneously.

Interesting gas-phase photocatalytic performance trends given in Fig. 6 can be elucidated by using the structural properties of the polymer-templated $\mathrm{TiO}_{2}$ microstructures shown in Scheme 3. The crosslinked polystyrene systems have typical glass transition temperatures $\left(T_{\mathrm{g}}\right)$ within $100-150^{\circ} \mathrm{C}$, above which the solid polymer tends to switch to a mobile molten/glassy state [23]. As can be seen from the specific surface area (SSA) results shown in Scheme 3, PsTi-200 sample has a moderately high SSA $\left(86 \mathrm{~m}^{2} / \mathrm{g}\right)$ suggesting that the mobilized PS-co-DVB microsphere template starts to segregate on the very top surface, only partially covering/blocking

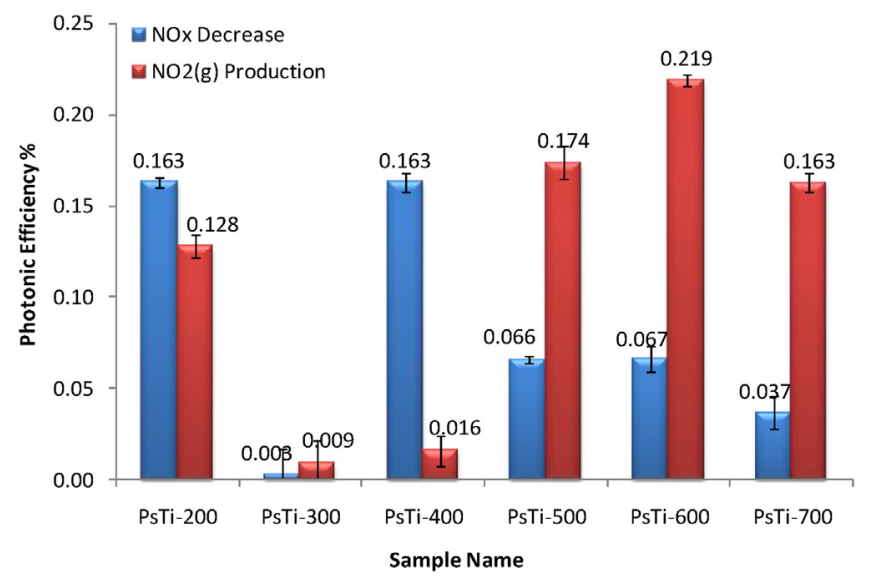

Fig. 6. Comparison of the photonic efficiencies of $\mathrm{TiO}_{2}$ microspheres/microbowls (For interpretation of the references to color in this figure legend, the reader is referred to the web version of this article.) 
Calcination Temperature, $\mathrm{IC}$
200

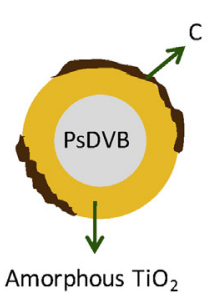

TiOX

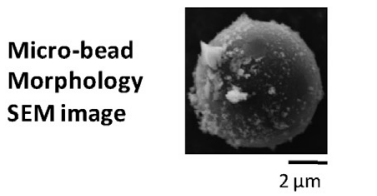

Powder color

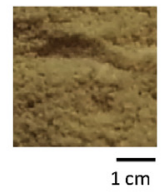

$86.4 \pm 0.7$
300

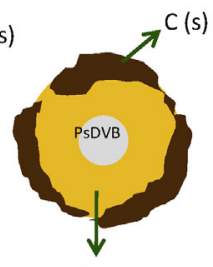

Amorphous $\mathrm{TiO}_{2}$

Pure anatase $(\mathrm{A})$

No recordable SEM

image due to

electron beam

damage $(10 \mathrm{kV})$

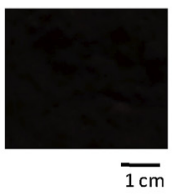

$47.7 \pm 1.3$
400

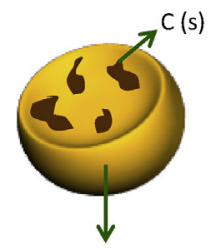

A
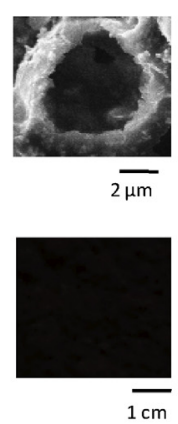

$159.4 \pm 0.6$
500
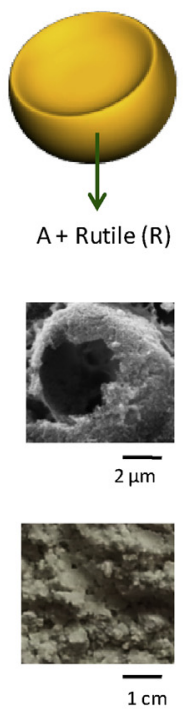

$13.9 \pm 0.1$
600
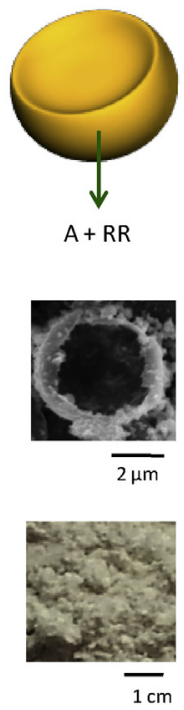

$8.5 \pm 0.03$
700
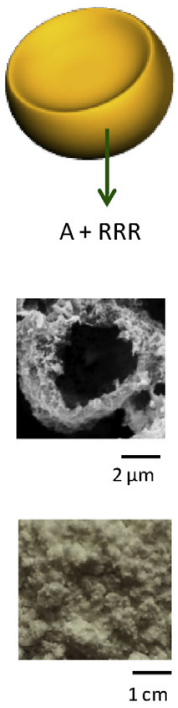

$6.9 \pm 0.02$

Weight fractions by XRD, \%

Anatase phase

100

78.4

73.1

34.6

Rutile phase

21.6

26.9

65.4

Scheme 3. Temperature-induced structural evolution of $\mathrm{TiO}_{2}$ microspheres/microbowls.

the amorphous $\mathrm{TiO}_{2} / \mathrm{TiO}_{x}$ coating on the microsphere system. Thus, at this calcination temperature, $\mathrm{TiO}_{2} / \mathrm{TiO}_{x}$ coating is still partially accessible for gas phase photocatalytic $\mathrm{NO}_{x}$ storage and $\mathrm{NO}_{2}$ (g) production (Fig. 6).

However, upon calcination at $300^{\circ} \mathrm{C}$, the SSA was observed to decrease by about $50 \%$, which is accompanied by a total loss of photocatalytic $\mathrm{NO}_{x}$ storage and $\mathrm{NO}_{2}(\mathrm{~g})$ production activities (Fig. 6). Apparently, calcination at $300^{\circ} \mathrm{C}$ leads to the segregation of the mobilized PS-co-DVB microsphere template onto the $\mathrm{TiO}_{2} / \mathrm{TiO}_{x}$ coating (Scheme 3). Hence, access to the photocatalytic active sites to $\mathrm{NO}(\mathrm{g})$ is completely blocked and the photocatalytic activity is entirely lost.

Increasing the calcination temperature to $400{ }^{\circ} \mathrm{C}$ shows a unique switch in the photocatalytic activity. This is the borderline temperature, where the PS-Co-DVB template starts to decompose leading to the rupture of the microspheres and formation of the microbowls. Formation of microbowls and elimination of the carbonaceous/polymeric film at $400^{\circ} \mathrm{C}$ is also fully consistent with the drastic increase in the SSA of the system to $159 \mathrm{~m}^{2} / \mathrm{g}$ (Scheme 3 ). The increase in the SSA is also accompanied by the formation of a cavity inside the microspheres due to the degradation of the PS-Co-DVB template, generating additional adsorption sites. At this temperature, Ti-coating reveals mostly an amorphous/porous nature, which also exhibits poorly crystalline anatase domains (Fig. 4). Thus, due to the decomposition/removal of the polymer template, most of the photocatalytic active sites on the amorphous Ti-coating become readily accessible and photocatalytic NO oxidation can be performed efficiently which is evident by the recovery of the photocatalytic $\mathrm{NO}_{x}$ storage (blue bar for PsTi-400 in Fig. 6). Although PsTi-400 sample can efficiently perform photocatalytic $\mathrm{NO}_{x}$ storage, yet it generates a relatively small amount of $\mathrm{NO}_{2}(\mathrm{~g})$. This could be due to the large SSA of the PsTi-400 sample with a large number of adsorption sites that can immediately capture
$\mathrm{NO}_{2}(\mathrm{~g})$ in the form of nitrites and nitrates on the $\mathrm{TiO}_{2}$ surface and prevent $\mathrm{NO}_{2}(\mathrm{~g})$ slip into the gas phase.

Fig. 6 shows that as the calcination temperature is increased from $400^{\circ} \mathrm{C}$ to $500^{\circ} \mathrm{C}$, the photocatalytic $\mathrm{NO}_{x}$ storage decreases significantly in contrast to the noticeable increase in the $\mathrm{NO}_{2}(\mathrm{~g})$ production. Within $400-500^{\circ} \mathrm{C}$, PsTi samples undergo a substantial crystallographic transformation (Fig. 4), where porous and amorphous $\mathrm{TiO}_{2}$ domains crystalize into ordered anatase and rutile domains resulting in a significant loss in the SSA. Along these lines, PsTi-500 sample has a SSA of $13.9 \mathrm{~m}^{2} / \mathrm{g}$ (Scheme 3 ). Thus, the photocatalytic $\mathrm{NO}_{x}$ storage capacity falls in line with the corresponding the SSA loss, suggesting that $\mathrm{NO}_{2}(\mathrm{~g})$ generated via photo-oxidation readily slips into the gas phase. However, this does not mean that the photocatalytic activity decreases upon increasing the temperature from $400^{\circ} \mathrm{C}$ to $500^{\circ} \mathrm{C}$. By comparing the combined $\mathrm{NO}_{x}$ storage and $\mathrm{NO}_{2}$ formation results (i.e. sum of the red and blue bars in Fig. 6) for $400^{\circ} \mathrm{C}$ and $500^{\circ} \mathrm{C}$ along with the corresponding SSA values suggests that PsTi-500 sample has a considerably higher per-site basis photocatalytic activity with respect to PsTi-400.

Fig. 6 indicates that the optimum gas-phase photocatalytic activity is reached for the PsTi-600 sample, which reveals a lower anatase/rutile ratio (Fig. 4a and Scheme 3 ) estimated by XRD results by using the approach developed by Spurr and Myers [35]. On the other hand, as the calcination temperature is increased to $700^{\circ} \mathrm{C}$, concomitant to the further decrease in the anatase/rutile ratio, photocatalytic activity starts to decrease. Thus, it is apparent that rather than the sole SSA values, crystallographic and electronic properties of the $\mathrm{TiO}_{2}$ microspheres/microbowls play a major role in determining their ultimate gas-phase photocatalytic activities.

\subsubsection{Solution-phase photocatalytic oxidation performance}

Photocatalytic activity of $\mathrm{TiO}_{2}$ microstructure calcined at different temperatures was also studied by conventional solution phase 


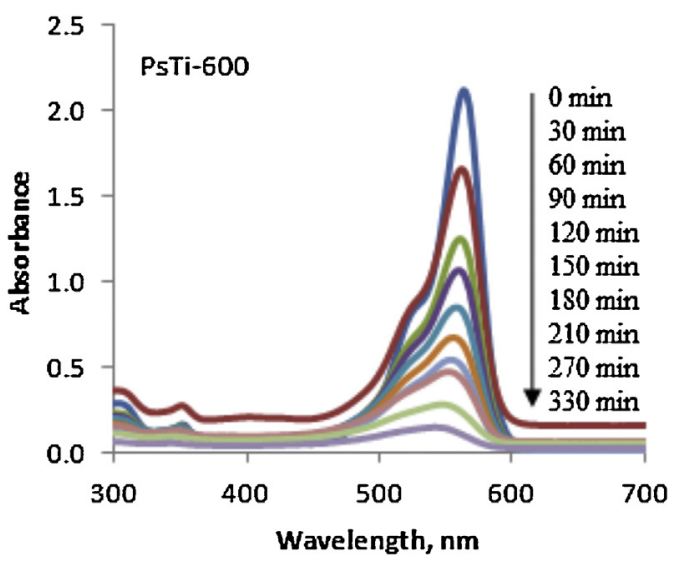

Fig. 7. Time-dependent UV-Vis absorption spectra showing UVA-induced photocatalytic degradation of $\mathrm{RhB}$ in the presence of PS-Co-DVB templated $\mathrm{TiO}_{2}$ microbowls calcined at $600^{\circ} \mathrm{C}$ for $2 \mathrm{~h}$.

photocatalytic oxidation of RhB. A typical series of time-dependent UV-vis absorption spectra obtained during the UVA irradiation is presented in Fig. 7. This series of spectra corresponds to the PsTi600 sample which is comprised of $\mathrm{TiO}_{2}$ microbowls (Fig. 2). During the photocatalytic reaction, the characteristic RhB absorption band located at $564 \mathrm{~nm}$ gradually decreases indicating photocatalytic degradation/oxidation of RhB. After 330 min of UVA irradiation, the dye solution becomes visibly colorless and the $564 \mathrm{~nm}$ signal vanishes almost completely.

Time-dependent decolorization efficiency results for the remaining samples are summarized in Fig. 8a. The solution phase photocatalytic oxidation experiments could not be realized for the PsTi-200 and PsTi-300 samples due to low density of the corresponding solid photocatalysts (originating from their high polymer content), which results in the floating of the microspheres on the
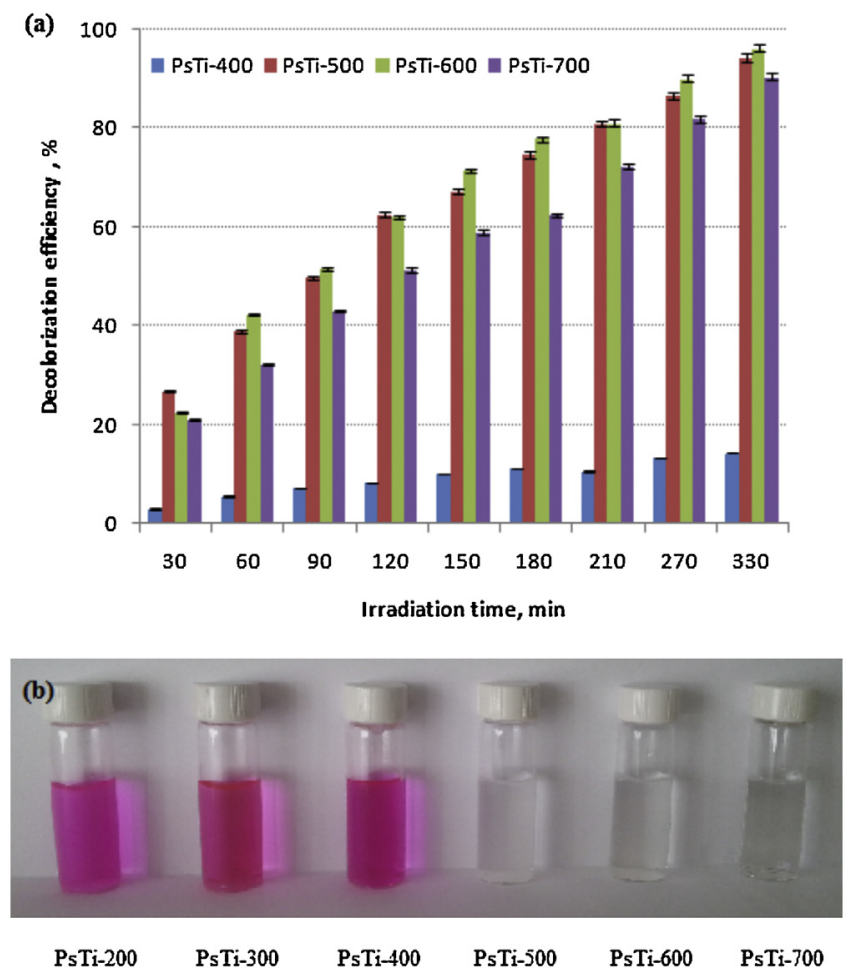

Fig. 8. (a) Liquid-phase photocatalytic reactivity of PS-co-DVB templated $\mathrm{TiO}_{2}$ microspheres/microbowls in Rhodamine B photodegradation via UVA irradiation, (b) photocatalyst-containing $1 \mathrm{mg} / \mathrm{L} \mathrm{RhB}$ solutions after $18 \mathrm{~h}$ UVA irradiation. aqueous medium preventing their efficient mixing and homogenous UVA exposure. Fig. 8a shows that RhB concentration in the solution decreases monotonically with increasing irradiation time which is also illustrated in Fig. 8b (for photocatalyst-containing $1 \mathrm{mg} / \mathrm{L} \mathrm{RhB}$ solutions after $18 \mathrm{~h}$ UVA irradiation). Control experiments performed by exposing $1 \mathrm{mg} / \mathrm{L}$ RhB solution to UVA in the absence of a photocatalyst (data not shown) did not lead to any decolorization under typical reaction conditions. The liquid-phase photocatalytic activity of the synthesized $\mathrm{TiO}_{2}$ structures exhibits a strong dependence on the calcination temperature. Fig. 8a clearly indicates that PsTi-600 sample which has a microbowl structure (Fig. 2) and exhibits predominantly anatase phase (in addition to rutile as a secondary phase) reveals the highest liquid-phase photocatalytic activity. The PsTi-400 sample is significantly less active than all of the analyzed samples (Fig. 8), and is comprised of a poorly crystalline anatase phase (Fig. 4). This suggests that solution-phase photocatalytic activity requires formation of ordered anatase/rutile crystallographic phases. On the other hand, Fig. 8a also shows that the solution-phase photocatalytic activity tends to decrease at elevated calcination temperatures such as $700^{\circ} \mathrm{C}$, suggesting that a rutile-dominant $\mathrm{TiO}_{2}$ microbowl structure is not favorable.

It is worth mentioning that the solution-phase photocatalytic reactivity trends presented in Fig. 8a cannot be explained solely based on the SSA values of the synthesized materials. Although PsTi-400 sample reveals a significantly higher SSA than all of the other synthesized materials, it has a considerably lower liquid-phase photocatalytic activity (Fig. 8). In other words, crystallographic and the electronic properties of the $\mathrm{TiO}_{2}$-coated Ps-co-DVB microspheres/microbowls seem to play a major role in their liquid-phase photocatalytic reactivity.

It is worth mentioning that we have also performed similar liquid-phase and gas-phase photocatalytic activity tests using a benchmark photocatalyst (P25) (Figs. S1 and S2, ESI $\dagger$ ). We observed that total photocatalytic activity for P25 in both liquid and gas phase experiments were about two times higher than that of the best Ps-co-DVB templated $\mathrm{TiO}_{2}$ microsphere/microbowl photocatalyst (PsTi-600). The SSA of P25 is about $50 \mathrm{~m}^{2} / \mathrm{g}$, which is about more than 5 times greater than that of PsTi-600. Thus, per-site basis photocatalytic activity of PsTi-600 is still 2.5 times higher than that of P25. This suggests that by optimizing the polymer microsphere templating strategy (for instance by using polymer nanospheres with smaller average particle sizes and thus higher SSA), advanced photocatalytic systems can be designed, which reveal higher photocatalytic performance both in terms of total photocatalytic activity as well as per-site-basis photocatalytic activity. In addition, further improvements in the photocatalytic performance of PS-co-DVB templated $\mathrm{TiO}_{2}$ microsphere/microbowl photocatalysts can also be achieved by incorporating plasmonic metal nanoparticles to these systems [36]. Such experimental efforts are currently underway in our research group [37].

\section{Conclusions}

In this work, Ps-co-DVB microsphere templated $\mathrm{TiO}_{2}$ photocatalysts were synthesized via sol-gel method. Influence of the calcination temperature on the structural properties and the photocatalytic activity of these systems under UVA excitation were investigated both in the gas phase (by studying photocatalytic $\mathrm{NO}(\mathrm{g})$ oxidation by $\left.\mathrm{O}_{2}(\mathrm{~g})\right)$ as well as in the solution phase (by monitoring Rhodamine $\mathrm{B}$ photocatalytic degradation). The polymer microspheres were found to be covered with a thin film of $\mathrm{TiO}_{2} / \mathrm{TiO}_{x}$ as well as $\mathrm{TiO}_{2} / \mathrm{TiO}_{x}$ nanoparticles. Photocatalytic activity carried out in the solution phase and in the gas phase showed that the photocatalyst calcined at $600^{\circ} \mathrm{C}$ exhibiting a microbowl structure, yielded the highest per-site-basis photocatalytic 
activity which is even greater than that of the commercial benchmark P25. Our findings indicate that not only the specific surface area but also the crystallographic and electronic properties of the $\mathrm{TiO}_{2}$ microstructures play a major role in determining their ultimate photocatalytic activities. This suggests that polymertemplated $\mathrm{TiO}_{2}$ microstructures offer a promising versatile synthetic platform for photocatalytic $\mathrm{DeNO}_{x}$ applications, which can be further improved by using polymer nanosphere templates with higher SSA or by additional functionalization with transition metal nanoparticles and/or plasmonic components.

\section{Acknowledgments}

Authors gratefully acknowledge Associate Prof. Dönüş Tuncel for fruitful discussions, and Zafer Say for performing BET measurements. E.O. also acknowledges financial support from Turkish Academy of Sciences through the "TUBA-GEBIP Outstanding Young Scientist Prize" and from Fevzi Akkaya Science Fund (FABED) through Eser Tümen Scientific Achievement Award as well as the Scientific and Technical Research Council of Turkey (TUBITAK) (Project Code: 109M713).

\section{Appendix A. Supplementary data}

Supplementary material related to this article can be found, in the online version, at http://dx.doi.org/10.1016/j. apsusc.2014.04.082.

\section{References}

[1] U. Diebold, The surface science of titanium dioxide, Surf. Sci. Rep. 48 (2003) $53-229$

[2] T.L. Thompson, J.T. Yates, Surface science studies of the photoactivation of $\mathrm{TiO}_{2}$ new photochemical processes, Chem. Rev. 106 (2006) 4428-4453.

[3] X. Chen, S.S. Mao, Titanium dioxide nanomaterials: synthesis, properties, modifications, and applications, Chem. Rev. 107 (2007) 2891-2959.

[4] A. Fujishima, X. Zhang, D.A. Tryk, $\mathrm{TiO}_{2}$ photocatalysis and related surface phenomena, Surf. Sci. Rep. 63 (2008) 515-582.

[5] M.A. Henderson, A surface science perspective on $\mathrm{TiO}_{2}$ photocatalysis, Surf. Sci. Rep. 66 (2011) 185-297.

[6] Y. Liu, J. Goebl, Y. Yin, Templated synthesis of nanostructured materials, Chem. Soc. Rev. 42 (2013) 2610-2653.

[7] C.N.R. Rao, A. Govindaraj, Synthesis of inorganic nanotubes, Adv. Mater. 21 (2009) 4208-4233.

[8] A.S. Attar, M.S. Ghamsari, F. Hajiesmaeilbaigi, S. Mirdamadi, K. Katagiri, K. Koumoto, Sol-gel template synthesis and characterization of aligned anatase$\mathrm{TiO}_{2}$ nanorod arrays with different diameter, Mater. Chem. Phys. 113 (2009) $856-860$.

[9] F. Cesano, D. Pellerej, D. Scarano, G. Ricchiardi, A. Zecchina, Radially organized pillars in $\mathrm{TiO}_{2}$ and in $\mathrm{TiO}_{2} / \mathrm{C}$ microspheres: synthesis, characterization and photocatalytic tests, J. Photochem. Photobiol., A: Chem. 242 (2012) 51-58.

[10] J. Hu, M. Chen, X. Fang, L. Wu, Fabrication and application of inorganic hollow spheres, Chem. Soc. Rev. 40 (2011) 5472-5491.

[11] T. Kang, A.P. Smith, B.E. Taylor, M.F. Durstock, Fabrication of highly-ordered $\mathrm{TiO}_{2}$ nanotube arrays and their use in dye-sensitized solar cells, Nano Lett. 9 (2009) 601-606

[12] I. Lee, J.B. Joo, Y. Yin, F. Zaera, A yolk@shell nanoarchitecture for Au/TiO 2 catalysts, Angew. Chem. Int. 50 (2011) 10208-10211.

[13] U. Meyer, A. Larsson, H. Hentze, R.A. Caruso, Templating of porous polymeric beads to form porous silica and titania spheres, Adv. Mater. 14 (2002) 1768-1772.
[14] A.S. Deshpande, D.G. Shchukin, E. Ustinovich, M. Antonietti, R.A. Caruso, Titania and mixed titania/aluminum, gallium, or indium oxide spheres: Sol-gel/template synthesis and photocatalytic properties, Adv. Funct. Mater 15 (2005) 239-245.

[15] J.H. Schattka, D.G. Shchukin, J. Jia, M. Antonietti, R.A. Caruso, Photocatalytic activities of porous titania and titania/zirconia structures formed by using a polymer gel templating technique, Chem. Mater. 14 (2002) 51035108.

[16] L. Yuan, S. Meng, Y. Zhou, Z. Yue, Controlled synthesis of anatase $\mathrm{TiO}_{2}$ nanotube and nanowire arrays via AAO template-based hydrolysis, J. Mater. Chem. A 1 (2013) 2552-2557

[17] D.A.H. Hanaor, C.C. Sorrell, Review of the anatase to rutile phase transformation, J. Mater. Sci. 46 (2011) 855-874.

[18] P. Zhang, C. Shao, Z. Zhang, M. Zhang, J. Mu, Z. Guo, Y. Sun, Y. Liu, Core/shell nanofibers of $\mathrm{TiO}_{2} @$ carbon embedded by $\mathrm{Ag}$ nanoparticles with enhanced visible photocatalytic activity, J. Mater. Chem. 21 (2011) 17746-17753.

[19] N.K.M.N. Srinivas, S.V. Rao, D.N. Rao, Saturable and reverse saturable absorption of Rhodamine B in methanol and water, J. Opt. Soc. Am. B: Opt. Phys. 20 (2003) 2470-2479.

[20] K. Sridharan, T.J. Park, Thorn-ball shaped $\mathrm{TiO}_{2}$ nanostructures: Influence of $\mathrm{Sn}^{2+}$ doping on the morphology and enhanced visible light photocatalytic activity, Appl. Catal., B: Environ. 134 (2013) 174-184.

[21] D. Yu, J.H. An, S.D. Ahn, S. Kang, K.S. Suh, Titanium dioxide/P(St-co-DVB)-MAA hybrid composite particles prepared by dispersion polymerization, Colloid Surf., A: Physicochem. Eng. Aspects 266 (2005) 62-67.

[22] E.D. Mekeridis, I.A. Kartsonakis, G.S. Pappas, G.C. Kordas, Release studies of corrosion inhibitors from cerium titanium oxide nanocontainers, J. Nanopart Res. 13 (2011) 541-554.

[23] S.E. Shim, S. Yang, H.H. Choi, S. Choe, Fully crosslinked poly(styrene-codivinylbenzene) microspheres by precipitation polymerization and their superior thermal properties, J. Polym. Sci., Part A: Polym. Chem. 42 (2004) $835-845$.

[24] S.M. Andonova, G.S. Şentürk, E. Kayhan, E. Ozensoy, Nature of the Ti-Ba interactions on the $\mathrm{BaO} / \mathrm{TiO}_{2} / \mathrm{Al}_{2} \mathrm{O}_{3} \mathrm{NO}_{x}$ storage system, J. Phys. Chem. C 113 (2009) 11014-11026.

[25] S.M. Andonova, G.S. Sentürk, E. Kayhan, E. Ozensoy, Fine-tuning the dispersion and the mobility of $\mathrm{BaO}$ domains on $\mathrm{NO}_{x}$ storage materials via $\mathrm{TiO}_{2}$ anchoring sites, J. Phys. Chem. C 114 (2010) 17003-17016.

[26] G.S. Sentürk, E.I. Vovk, V.I. Zaikovskii, Z. Say, A.M. Soylu, V.I. Bukhtiyarov, E. Ozensoy, $\mathrm{SO}_{x}$ uptake and release properties of $\mathrm{TiO}_{2} / \mathrm{Al}_{2} \mathrm{O}_{3}$ and $\mathrm{BaO} / \mathrm{TiO}_{2} / \mathrm{Al}_{2} \mathrm{O}_{3}$ mixed oxide systems as $\mathrm{NO}_{x}$ storage materials, Catal. Today 184 (2012) 54-71.

[27] T. Giannakopoulou, N. Todorova, G. Romanos, T. Vaimakis, R. Dillert, D. Bahnemann, C. Trapalis, Composite hydroxyapatite $/ \mathrm{TiO}_{2}$ materials for photocatalytic oxidation of $\mathrm{NO}_{x}$, Mat. Sci. Eng. B 177 (2012) 1046-1052.

[28] A. Mitsionis, T. Vaimakis, C. Trapalis, N. Todorova, D. Bahnemann, R. Dillert Hydroxyapatite/titanium dioxidenanocomposites for controlled photocatalytic NO oxidation, Appl. Catal., B: Environ. 106 (2011) 398-404.

[29] Y. Lin, Y. Tseng, J. Huang, C.C. Chao, C. Chen, I. Wang, Photocatalytic activity for degradation of nitrogen oxides over visible light responsive titania-based photocatalysts, Environ. Sci. Technol. 40 (2006) 1616-1621.

[30] Y. Tseng, C. Kuo, C. Huang, Y. Li, P. Chou, C. Cheng, M. Wong, Visible-lightresponsive nano- $\mathrm{TiO}_{2}$ with mixed crystal lattice and its photocatalytic activity Nanotechnology 17 (2006) 2490-2497.

[31] N. Negishi, K. Takeuchi, T. Ibusuki, Surface structure of the $\mathrm{TiO}_{2}$ thin film photocatalyst, J. Mater. Sci. 33 (1998) 5789-5794

[32] T. Sano, N. Negishi, K. Koike, K. Takeuchi, S. Matsuzawa, Preparation of visiblelight-responsive photocatalyst from complex of $\mathrm{Ti}_{4}{ }^{+}$with nitrogen-containing ligand, J. Mater. Chem. 14 (2004) 380-384.

[33] R. Hummatov, O. Gülseren, E. Ozensoy, D. Toffoli, H. Üstünel, First-principles investigation of $\mathrm{NO}_{x}$ and $\mathrm{SO}_{x}$ adsorption on anatase-supported $\mathrm{BaO}$ and $\mathrm{Pt}$ overlayers, J. Phys. Chem. C 116 (2012) 6191-6199.

[34] O. Carp, C.L. Huisman, A. Reller, Photoinduced reactivity of titanium dioxide Prog. Solid State Chem. 32 (2004) 33-177.

[35] R.A. Spurr, H. Myers, Quantitative analysis of anatase-rutile mixtures with an X-ray diffractometer, Anal. Chem. 29 (1957) 760-762.

[36] J. Lu, P. Zhang, A. Li, F. Su, T. Whang, Y. Liu, J. Gong, Mesoporous anatase $\mathrm{TiO}_{2}$ nanocups with plasmonic metal decoration for highly active visible-light photocatalysis, Chem. Commun. 49 (2013) 5817-5819.

[37] D.A. Erdogan, M. Polat, E. Ozensoy, (in preparation) 